\title{
Dermo-Fascial Suspension in Mastopexy for Improvement of Aesthetic Outcomes
}

\author{
IBRAHIM H. KAMEL, M.D. \\ The Department of Plastic and Reconstructive Surgery, Faculty of Medicine, Ain Shams University, Cairo, Egypt
}

\begin{abstract}
Background: Mastopexy is the art of restoring breast volume and its youthful appearance.

Aim: We present a surgical technique for simultaneous mastopexy using auto-augmentation by superiorly based dermoglandular flap. In addition, we use two dermo-facial flaps to support the breast tissue in high position to restore and maintain central mound projection and elevate inframammary fold.
\end{abstract}

Patients and Methods: Auto-augmentation mastopexy was performed for 36 patients using vertical superior pedicle deepithelialized dermoglandular flap that inserted beneath the breast tissue. Two opposing dermo-facial flaps based on medial and lateral pillars along the vertical line were used to support the deepithelialized dermoglandular tissue that sutured to anterior chest wall and to each other.

Results: During follow-up period there was no bottoming out of breast tissues or other major adverse effects except for mild asymmetry in early 3 patients and patients showed high rate of satisfaction by the results. The results confirmed that this technique corrects ptosis while increasing the projection and apparent volume of the breast and keep inframammary fold (IMF) in high position with minimal degree of descend which is parallel to that of the nipple.

Conclusion: The combined use of dermo-fascial flap to support the glandular tissue with auto-augmentation mastopexy improves the shape; projection and contour of the breast and it also help to have long lasting results. The advantage of the technique is that it optimizes the shape and volume of the breast and creating a narrow breast base with a new high inframammary fold without the use of an implant. With this technique recurrent breast ptosis can be minimized after mastopexy procedures.

Evidence Based Medicine: Level IV, case series.

Key Words: Dermo-fascial flap - Superficial fascia - Mastopexy-breast lift-Bottoming out-inframammary crease.

\section{INTRODUCTION}

The breast is surrounded by the anterior and posterior layers of superficial fascia [1]. The anterior layer of superficial fascia is separating dermis from glandular tissue. While posterior layer extends to underlying pectoralis muscle fascia through fascial extensions. As breast size increases, these connections become looser as a result of gravitational forces $[2,3]$.

Breast ptosis results from weakening and lengthening of the supporting structures of the breast [4]. Therefore, correction of ptosis and restoring youthful breasts remains a challenge in breast aesthetic surgery. Thus, successful mastopexy combines a pleasing skin pattern to reduce the size of breast envelope and a pedicle of breast tissue that maintains nipple viability and support breast lift [5].

Dermal suspension alone without glandular reshaping for correction of ptosis has been used as a classic treatment, however, it did not achieve adequate long-term outcome [6-9]. Other techniques that used synthetic materials or suspension sutures to overcome ptosis recurrence also did not gain wide acceptance $[\mathbf{1 0 , 1 1 ]}$ the use of dermofascial suspension by means of the anterior layer of superficial fascia and overlying dermis to the deep (pectoral) fascia has been described [12,13,33].

This study presents a surgical technique for autoaugmentation mastopexy using superiorly based dermoglandular flap combined with the use of two dermo-facial flaps. These flaps serve for supporting the breast tissue in high position behind the upper pole to restore central mound projection, narrowing the lower breast base, and raising the inframammary crease with minimal tension skin repair.

\section{PATIENTS AND METHODS}

This study included 36 female patients (72 breasts) complaining of third-degree breast ptosis [14] without breast enlargement from January 2012 - December 2015. All patients were adult patients without associated any medical or surgical comorbidity. Detailed history taking and physical examination were performed. NAC position in relation to inframammary fold and to the supraster- 
nal notch were recorded. Preoperative mammogram and/or breast ultrasound was done for all patients to exclude presence of non-palpable breast masses. The benefits and possible drawbacks were discussed, and informed consent was obtained.

Preoperative markings: Patients were marked in the upright position. The breast meridian, inframammary fold (IMF), suprasternal notch to nipple (SN-N) distance, and nipple to inframammary fold distance (N-IMF) were marked and recorded. The future NAC superior border was determined by projecting the inframammary fold onto the anterior breast skin. The future SN-N distance ranged between $19-22 \mathrm{~cm}$. Skin incisions were marked using the Mosque-type pattern around the nipple in a curvilinear fashion and end $2-4 \mathrm{~cm}$ from IMF [15]. The extent of the breast tissue excision was determined by lateral and medial breast displacement technique. The width of the superior pedicle ranged from $8-11 \mathrm{~cm}$. The circumference of the nipple areola complex was marked with a $42-45 \mathrm{~mm}$ diameter cookie. Two dermofascial flaps were marked in a semicircular fashion along the vertical lines.

Surgical technique (Figs. 1,2): The pedicle was de-epithelialized first then the pre-marked two dermo-fascial flap including the deep dermis and the anterior layer of the superficial fascia were dissected as one unit based on medial and lateral pillars. NAC was transposed to the new position
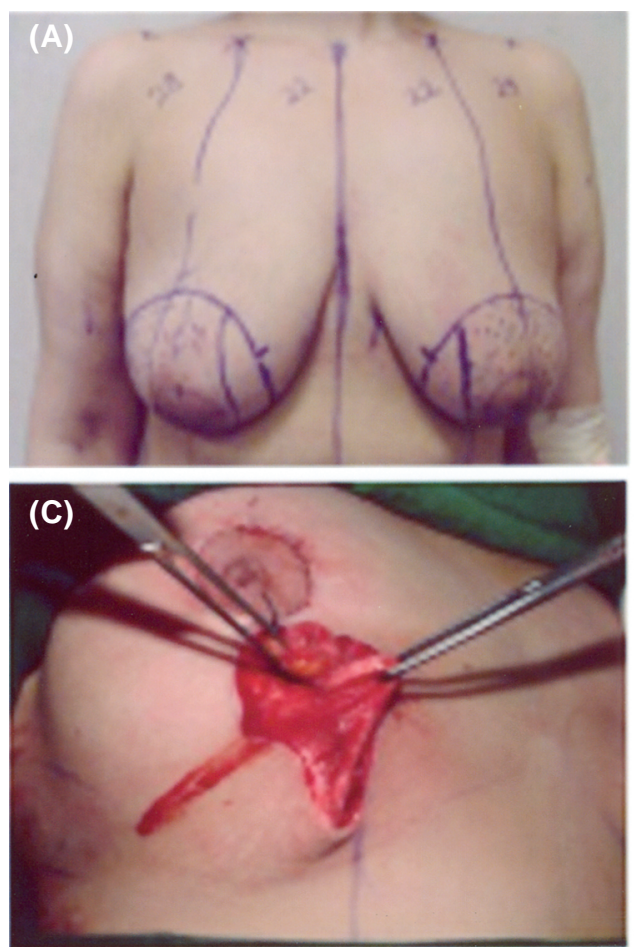

Fig. (2): (A) Preoperative marking showing the superior pedicle, (B) The dermo-fascial flaps are based on medial and lateral

pillars, (C) The glandular flaps are sutured for auto-augmentation, and the two opposing dermo-fascial flaps are sutured
to chest wall and to each other, (D) The right breast after suturing the dermo-fascial flaps showing the high new IMF.

pillars, (C) The glandular flaps are sutured for auto-augmentation, and the two opposing dermo-fascial flaps are sutured
to chest wall and to each other, (D) The right breast after suturing the dermo-fascial flaps showing the high new IMF. at higher level based on the superior dermoglandular pedicle. The two pillars were sutured to support the dermoglandular pedicle and to achieve the desired shape and fullness. One of the dermofascial flaps (usually the lateral first) was sutured to the anterior chest wall at higher level (usually periostuim of the $4^{\text {th }}$ and $5^{\text {th }}$ costal cartilages medially and ribs laterally) by two or three stitches using 2-0 permanent sutures. Then a small releasing incision was done at the upper edge of the first flap to facilitate the passage of the other dermofascial flap. With a good retraction of the breast tissue by the assistant surgeon, the flap is sutured to the rib periostuim nearly at the same level. Care must by taken to avoid asymmetry of the IMF level on both sides. Finally, the dermo-fascial flaps were sutured to each other to support the glandular flaps.

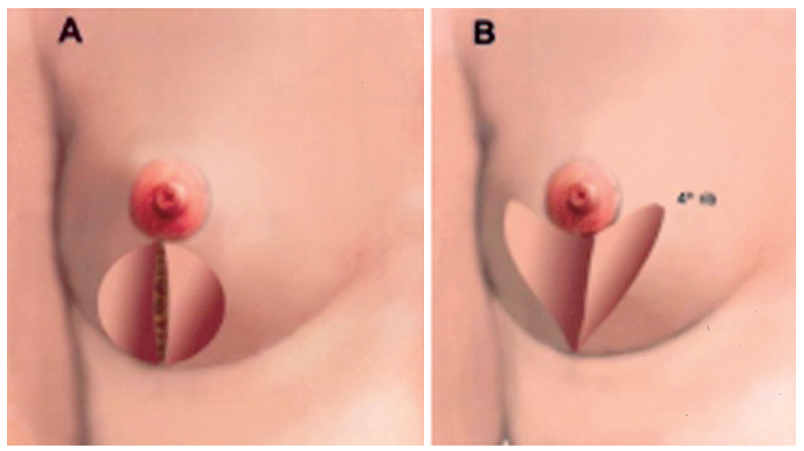

Fig. (1): A simplified diagram showing the surgical technique, (A) The 2 dermofascial flaps are dissected, (B) The flaps are sutured to perichondruim of the $4^{\text {th }}$ rib.
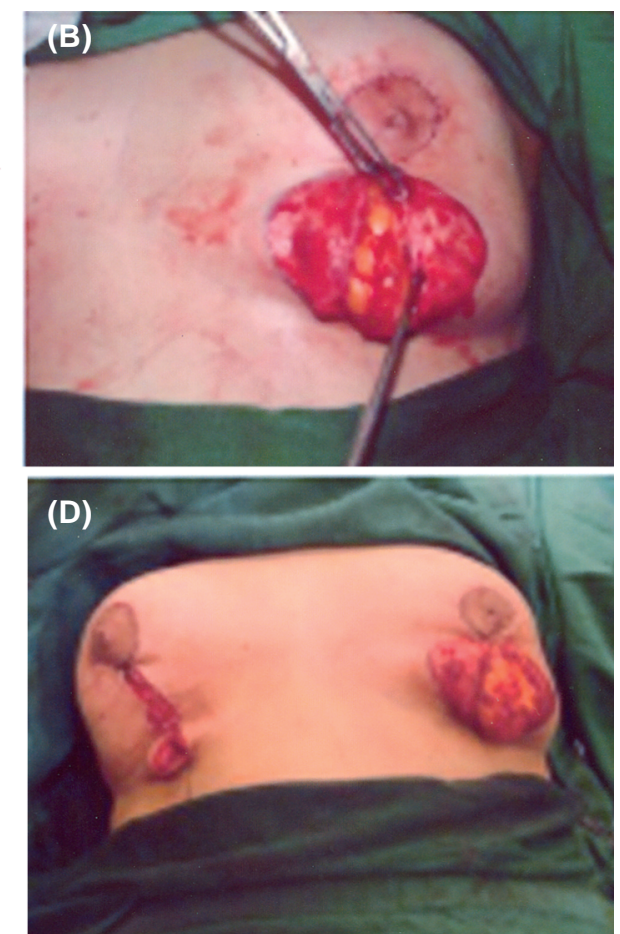
Drains are usually used and removed within 25 days. Patients are discharged the same day or stay for 1 night. Intravenous antibiotics were given at the start of the surgical procedure for 24 hours then patients continue oral antibiotics for another 5 days.

Follow-up is weekly in the first month, then every 3 months for 18 months. Digital photos were taken preoperatively and postoperatively. Results were interpreted by comparing the measurements of the SN-N distance and the N-IMF distance preoperatively, 6 months postoperative, and at 18 months postoperative. Statistical analysis of the measurements was performed using (SPSS version 15). Clinical evaluation regarding the aesthetic outcome was also graded as excellent (>75\% improvement), good (50-75\% improvement), and fair ( $<50 \%$ improvement) based on evaluation by a panel of surgeon assessment, independent surgeon assessment, and patient satisfaction. These assessment criteria are simplified questionnaire that are adopted from (the breast-Q) scale [16] and included overall breast shape, ptosis recurrence, nipple areola position and shape, breast size, scar quality, lactation, and relief of psychosocial and sexual symptoms.

The incidence of complications was also recorded including seroma, hematoma, wound dehiscence, wound infection, and abnormal scarring.

\section{RESULTS}

Thirty-six female patients (72 breasts) were included with age ranged between 28-51 years (mean age of 37.6 years). Patients' weight ranged from $52-88 \mathrm{~kg}$ with a mean of $66.9 \mathrm{~kg}$ and body mass index ranged from 24.2-32.5 with a mean of 27.2. All surgical procedures were done under general anesthesia and by the same surgical team. Follow-up ranged from 18-46 months with mean of 20.2 months.

Satisfactory aesthetic improvement in breast shape and nipple projection could be obtained in all patients; 26 patients had excellent result and ten patients had good results and no patient had fair result (Figs. 3,4). This high rate of patient satisfaction was maintained at the 6 and 18 months postoperative with minimal changes that did not affect overall outcome.

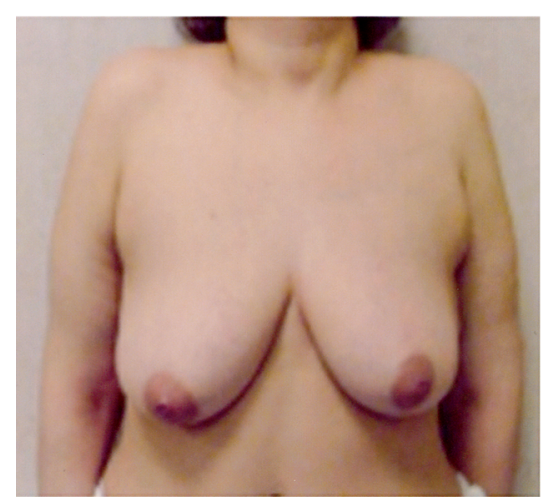

(A)

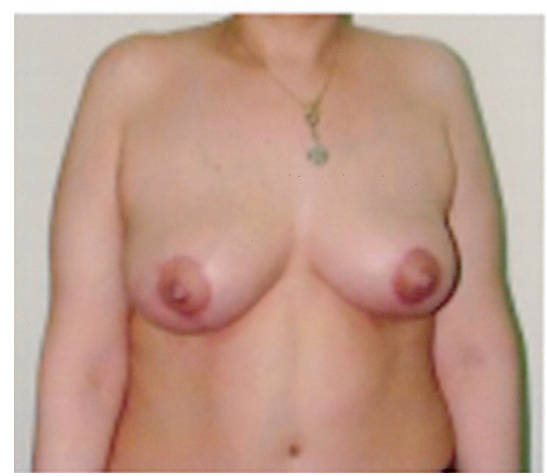

(D)

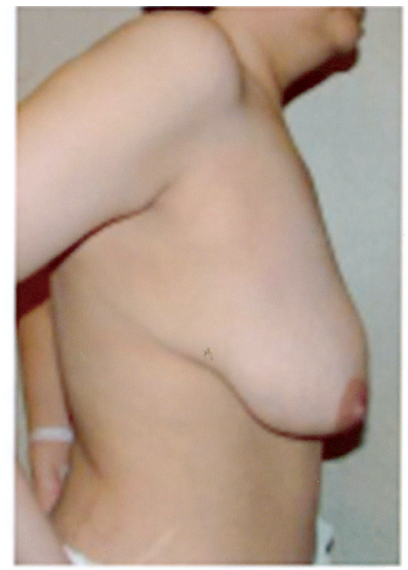

(B)

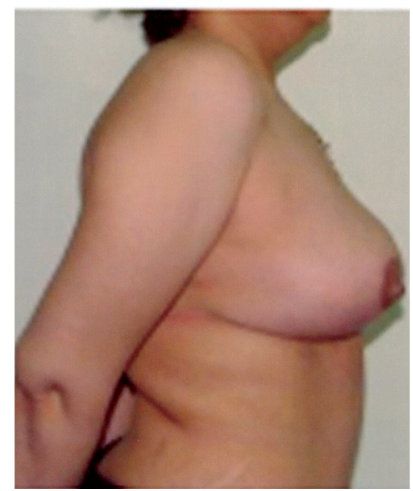

(E)

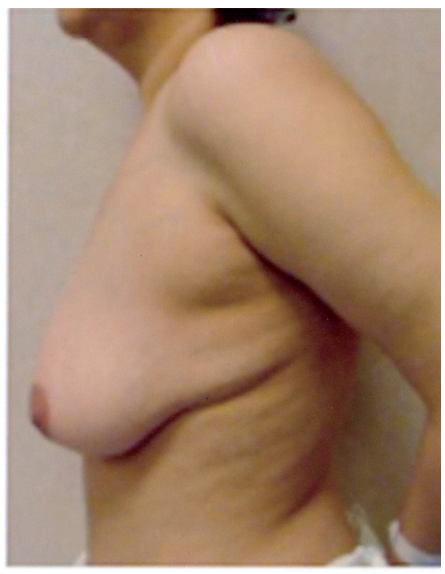

(C)

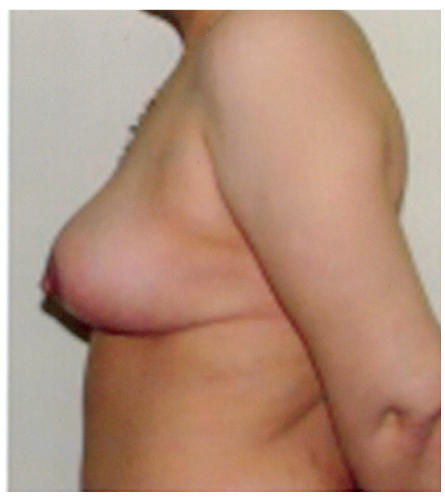

(F)

Fig. (3): (A-C) Preoperative views of 38 years female patient, (D-F) Six months postoperative views. 


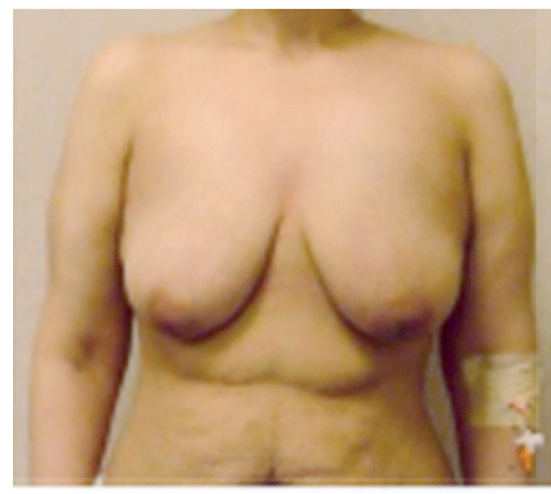

(A)

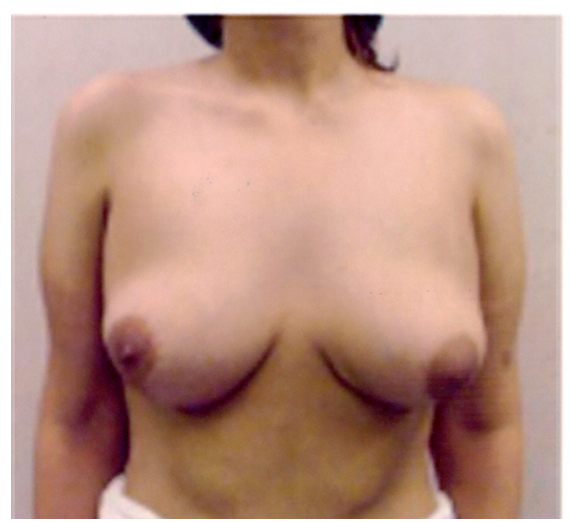

(D)

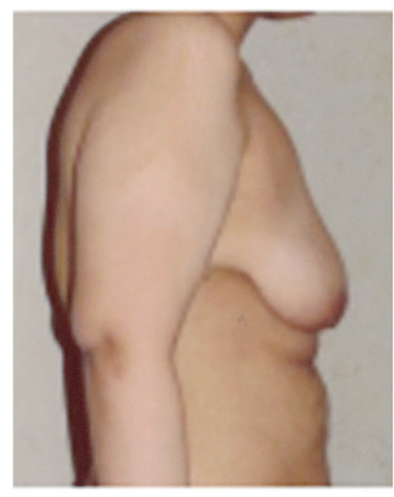

(B)

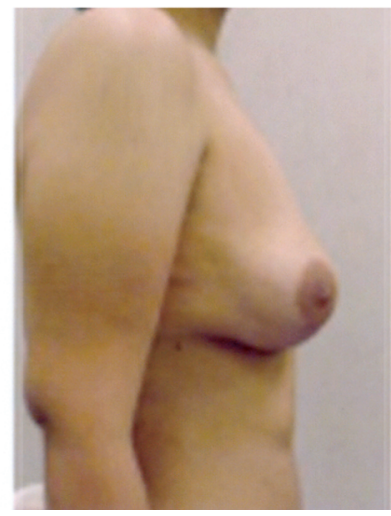

(E)

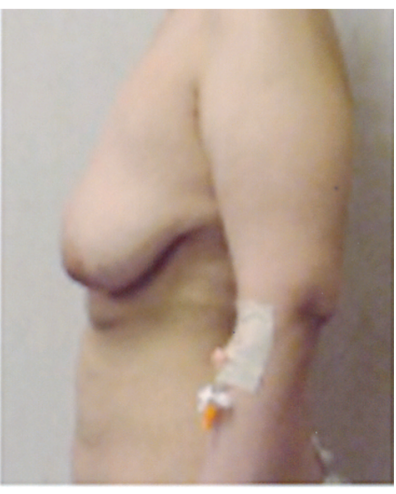

(C)

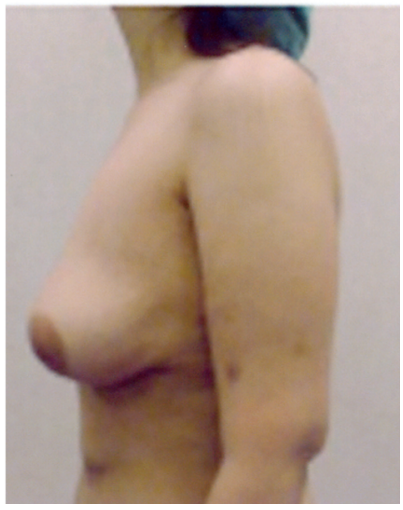

(F)

Fig. (4): (A-C) Preoperative views of 35 years female patient, (D-F) 3 years postoperative views.

Statistical analysis of the SN-N and N-IMF distances confirmed these clinical findings. The mean values and standard deviation of the SN-N distances are shown in Tables $(1,2)$. Statistical analysis showed that there is a high statistical significance difference between three measurements of SN distance. The mean values and standard deviation of the N-IMF distances are shown in Tables $(3,4)$. Statistical analysis showed that there is a high statistical significance difference between three measures of N-IMF distance. Correlating the $\mathrm{SN}-\mathrm{N}$ and N-IMF measurements revealed that there is positive weak correlation between the postoperative $\mathrm{SN}-\mathrm{N}$ and N-IMF at 6 and 18 months (Table 5). This correlation was significant at 6 months measures but not significant at 18 months.

Three patients had mild asymmetry. No other complications were reported such as pigmented or hypertrophic scars, wound dehiscence, or NAC malposition. No revision surgery was needed in any patient.
Table (1): Statistical significance difference between three measurements of SN distance. Post hoc LSD test shows that this difference between the three measures ( $p$-value 0.001$)$.

\begin{tabular}{lcccc} 
SN-N & Mean & SD & $\begin{array}{c}\text { Repeated } \\
\text { measures ANOVA } \\
\text { (test of significance) }\end{array}$ & $\begin{array}{c}p- \\
\text { value }\end{array}$ \\
\hline Pre-SN-N & 27.222 & 1.77 & & \\
Post6-SN-N & 21.667 & 1.13 & 11728.889 & $0.001^{*}$ \\
Post18-SN-N & 23.083 & 1.30 & & \\
\hline
\end{tabular}

*Sig. $p$-value.

Table (2): Statistical significant difference between SN distance breast measurements.

\begin{tabular}{|c|c|c|}
\hline $\begin{array}{l}\text { SN-N } \\
\text { measures }\end{array}$ & $\begin{array}{c}\text { Mean } \\
\text { difference }\end{array}$ & $\begin{array}{c}\text { Pairwise comparison } \\
\text { Sig. (a) }\end{array}$ \\
\hline 12 & $5.55(*)$ & $.000 *$ \\
\hline 3 & $4.139(*)$ & $.000 *$ \\
\hline 21 & $-5.55(*)$ & $.000 *$ \\
\hline 3 & $-1.414(*)$ & $.000 *$ \\
\hline 31 & $-4.139(*)$ & $.000 *$ \\
\hline 2 & $1.414(*)$ & $.000 *$ \\
\hline
\end{tabular}

1: Pre SN-N. 2: Six SN-N. 3: Year SN-N. 
Table (3): Statistical significance difference between three measurements of N-IMF distance. Post hoc LSD test shows that this difference between the three measures ( $p$-value 0.001).

\begin{tabular}{lcccc}
\hline $\begin{array}{l}\text { N-IMF } \\
\text { measures }\end{array}$ & Mean & SD & $\begin{array}{c}\text { Repeated } \\
\text { measures ANOVA } \\
\text { (test of significance) }\end{array}$ & $\begin{array}{c}p \text { - } \\
\text { value }\end{array}$ \\
\hline Pre-N-IMF & 9.528 & 9.53 & & \\
Post6-N-IMF & 6.882 & 6.88 & 3980.385 & $0.00 *$ \\
Post18-N-IMF & 7.750 & 7.75 & & \\
\hline
\end{tabular}

Table (4): Statistical significant difference between N-IMF distance breast measurements.

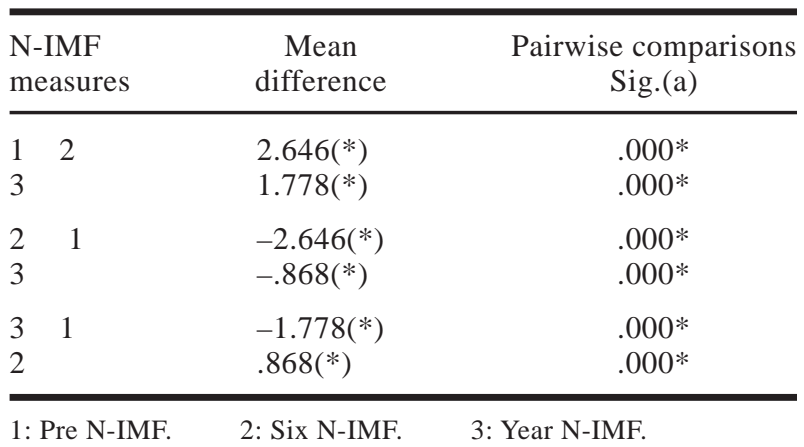

Table (5): Correlation between the postoperative SN-N and $\mathrm{N}$-IMF at 6 and 18 months.

\begin{tabular}{lc}
\hline $\mathrm{N}=36$ & Post 6-N-IMF \\
\hline Post $6-S N-N$ : & \\
Pearson correlation & 0.356 \\
$p$-value & $0.03^{*}$ \\
\hline $\mathrm{N}=36$ & Post $18-\mathrm{N}-\mathrm{IMF}$ \\
\hline Post $18-S N-N$ : & \\
Pearson correlation & 0.307 \\
p-value & 0.06 \\
\hline
\end{tabular}

*Sig. $p$-value.

N.B.: This correlation was significant at 6 month measures but not significant at 18 month.

\section{DISCUSSION}

Mastopexy presents one of the most challenging procedures in breast cosmetic surgery. It aims at reshaping of the breast to restore a youthful natural shape. According to the national DATA bank statistics in 2015, more than 148,967 patients underwent breast lift surgery; 5th most common cosmetic procedure [17]. The decision making to perform mastopexy alone, augmentation alone, and augmentation mastopexy depend on the location of NAC to IMF [18].

Auto-augmentation mammoplasty is a good option for patients who want to augment their breasts without use of breast implant. Auto- augmentation mastopexy corrects ptosis, increase breast projection and apparent volume. It is redistribution of breast tissue from the area with excess tissue to an area with less tissue. It can be done using inferior pedicle or vertical pedicle. The inferior pedicle is less superior compared to supperior pedicle flap as it connot be folded on itself [19].

Goes was the first to demonstrate that dermal mastopexy alone with minimal manipulation of the underlying breast parenchyma failed to maintain long-term results. He advocated the use of periareolar dermal flap and mesh to support the breast tissue [20,21]. Other studies using foreign materials to support breast have been described, however these techniques did not gain wide acceptance among surgeons $[\mathbf{1 0 , 2 2 , 2 3 ]}$. Suspension sutures has been described to overcome the weight of the remaining breast tissue on the integument but did not also gain widespread $[\mathbf{3 , 2 3 , 2 4 ]}$.

The work of Goes made attention on the role of internal parenchymal reshaping [18]. Foustanos and Zavrides [25] and Boehm et al. [26] described the double-flap technique. They used inferior pedicle and medial and lateral pillars. The inferior flap is sutured to the pectoral fascia, and the medial and lateral pillars are sutured together. The only difference was the skin closure pattern. Other authors used part of the pectoralis muscle to support the inferior pedicle flap [27,28].

However, these techniques violate the tissue compartments and raised oncologic concerns as, the standard oncologic treatment includes removing one normal tissue layer beyond the one involved with cancer [29]. The next anatomical layer is the chest wall itself in Graf \& Biggs [28] technique and the pectoralis muscle in the Ritze et al., technique [27].

It is clear that the maintenance of the breast shape in inferior pedicle techniques relies mainly on the skin envelope and the gravity effects can result in recurrent ptosis. In addition, the resulting skin tension to maintain breast shape, may result in obvious scars as well [4]. Therefore, our choice was the use of superior pedicle which is less vulnerable to gravitational forces.

Correction of ptosis requires dissection of the breast from underlying pectoral fascia and anchoring it to superior position. Marchac and deOlarte [30] Lejour [31,32] achieved that through upper glandular placation and suspension to the pectoralis fascia. Dermofascial suspension by the anterior layer of superficial fascia and dermis has been 
described to achieve this goal also $[\mathbf{1 2 , 1 3 ]}$. The use of dermofascial flap to support the undermined and elevated superior pole is better than the use of the chest wall-based flaps designed by Graf \& Biggs [28] and Ritze et al. [27].

In 1990s, Loockwood presented the superficial facial system (SFS) as the primary structural support of the skin and fat of the body. He stated that the anterior layer of the superficial fascia is an indistinct fibrofatty layer that is separate from the overlying dermis and underlying breast tissue. This layer can be used for suspension of high tension wound repair of the breast contouring procedures $[3,33]$.

The breast SFS is a distinct layer formed of collagen bundles parallel to the skin surface and interrupted by some elastic fibers with a thickness ranging from $1.5-3.0 \mathrm{~mm}$ [34]. Recently, we used the dermo-fascial suspension in cases of gigantomastia during reduction mammoplasty. Our results showed very satisfactory results clinically that is confirmed statistically [35].

In this work, we used the SFS not only to support breast tissue in higher position but also for reshaping. We used 2 opposing dermofascial flaps that sutured to each other and to anterior chest wall. Our results showed that suspension by dermo-fascial flaps can correct breast ptosis. In addition, the design of 2 opposing flaps improve the definition of the inframammary fold (IMF) and keep the IMF in high position with mild degree of descend during follow-up period and generally parallel to that of nipple. These flaps also allowed tension free closure of the skin.

Statistical analysis showed high statistically significant difference between the preoperative and postoperative measurements which is logic. However, there is a statistically significant difference between measurements at 6 and 18 months. By reviewing the mean values of $\mathrm{SN}-\mathrm{N}$ measures, they were $21.6 \mathrm{~cm}$ and $23 \mathrm{~cm}$ at 6 and 18 months respectively. N-IMF measures also showed $6.88 \mathrm{~cm}$ and $7.7 \mathrm{~cm}$ at 6 and 18 months respectively. Van Deventer et al. [4] reported nearby postoperative measurements generally but not at specific postoperative dates. Furthermore, these results are comparable to those obtained by Hönig et al. [19]. They also reported a descent of the SN-N \& N-IMF measurements by about $20 \%$ at 12 months postoperative. This descent cannot be considered as recurrent ptosis which is defined by Stevens et al. [36] as an acceptable initial result that later "bottomed out" over time. Accordingly, this poor aesthetic outcome had not been recorded in our cases. Migliori [37] also considered recurrence when the NAC drops more than $2 \mathrm{~cm}$ after 1 year postoperative. We did not record this drop in our patients even at 18 months postoperative.

It seems also that this mild descent is an inevitable process and no surgical technique is able to eliminate the gravitational forces completely. In conclusion, although there is a statistical difference at 6- and 18-months measurements, this difference does not have the same significance from clinical point of view.

Although the inverted-T incision was found to be the most common type of mastopexy performed in US [38]. We prefer the short scar technique as it is less liable for wound problems like wound dehiscence especially at the junction of vertical and horizontal limbs. The tendency of scars visibility in our population also favors us to minimize scars as much as possible. Short scar can be sufficient in most of cases, even for those with high $\mathrm{SN}-\mathrm{N}$ distances. However, in certain circumstances, it cannot replace the inverted-T incision closure.

\section{Conclusion:}

Mastopexy is not a simple technique; it is the art of restoring a youthful appearance by contouring the breast to improve; shape and creating welldefined inframammary fold with minimal scarring. Our results show that the dermo-fascial support by the superficial fascial system of the breast in mastopexy procedures is an effective technique to achieve these goals.

\section{REFERENCES}

1- Romrell L. and Bland K.I.: Anatomy of the breast, axiilla, chest wall, and related metastatic sites. In Bland K.I. and Copeland E.M. (eds.): The breast; comprehensive management of benign and malignant diseases. Philadelphia; Saunders Company, 1991.

2- Bostwick J.: Plastic and reconstructive breast surgery. St. Louis: Quality Medical Publishing, p. 67, 1990.

3- Lockwood T.E.: Superficial fascial system (SFS) of the trunk and extremities: A new concept. Plast. Reconstr. Surg., 87: 1009, 1991.

4- Van Deventer P.V., Graewe F. and Würinger E.: Improving the Longevity and results of mastopexy and breast reduction procedures: Reconstructing an internal breast support system with biocomppatible mesh to replace the supporting function of the ligamentous suspension. Aesth. Plast. Surg., 36: 578-589, DOI 10.1007/s00266-011-9845-2, 2012.

5- Singh D., Forte A.J., Apostolides J., Zahiri H.R., Stromberg J. and Alonso N.: Z-Mammoplasty: A novel concept in mastopexy. E Plasty, 11: e29, 2011. 
6- Strombeck J.: Loockwood. Mammoplasty: Report on new technique based on the two-pedicle technique. Br. J. Plast. Surg., 13: 79, 1960.

7- McKissock P.: Reduction mammoplasty with a vertical dermal flap. Plast. Reconstr. Surg., 49: 245, 1972.

8- Hindrer U.: The dermal breastiere mammoplasty. Clin. Plast. Surg., 3: 349, 1976.

9- Goulian D.Jr.: Dermal mastopexy. Plast. Reconstr. Surg., 47: 105, 1971.

10- Bustos R.A.: Periareolar mammoplasty with silicone supporting lamina. Plast. Reconstr. Surg., 89: 646-657, 1992.

11- Johnson G.W.: Central core reduction mammoplasties and Marlex suspension of breast tissue. Aesthet. Plast. Surg., 5: 77-84, 1981 .

12- Grotting J.C., Marx A.P. and Chen S.M.: Masatopexy. In Mathes S.J. (ed.): Plastic Surg. $2^{\text {nd }}$ edition, Philadelphia; Elsevier Inc., p. 47, 2006.

13- Awad M., Al-Leithy I.M., Abd-Aal M. and Mahmoud N.: Dermofascial suspension of the breast in cases of gigantomastia. Egypt. J. Plast. Reconstr. Surg., 30: 171, 2006.

14- Regnault P.: Breast ptosis: Definition and treatment. Clin. Plast. Surg., 34 (2): 193-203, 1976.

15- Rohrich R.J., Thornton J.F., Jakubietz R.G., Jakubietz M.G. and Grünert J.G.: The limited scar mastopexy: Current concepts and approaches to correct breast ptosis. Plast. Reconstr. Surg., 114: 1622-1630, 2004.

16- Pusic A.L., Klassen A.F., Scott A.M., Klok J.A., Cordeiro P.G. and Cano S.J.: Development of a new patient-reported outcome measure for breast surgery: The breast-Q. Plastic \& Reconst. Surgery, 124 - Issue 2: 345-353, 2009.

17- The American Society for Aesthetic Plastic Surgery, cosmetic surgery national data bank statistics, 2015.

18- Nahabedian M.: Breast deformities and mastopexy. Plast. Reconstr. Surg., 127: 91e, 2011.

19- Hönig J.F., Frey H.P., Hasse F.M. and Hasselberg J.: Autoaugmentation mastopexy with an inferior-based pedicle. Aesth. Plast. Surg., 33: 302-307, DOI 10.1007/s00266-009-9310-7, 2009.

20- Goes J.C.S.: Periareolar mammoplasty with mixed mesh support: The double skin technique. Plast. Reconstr. Surg., 89: 459-467, 1992.

21- Goes J.C.S.: Periareolar mammoplasty: Double skin technique with application of polyglactin or mixed mesh. Plast. Reconstr. Surg., 97: 959-968, 1996.

22- Ryan J.J. and Alowen: Thoracic advancement flap in breast reconstruction aafter mastectomy. Plast. Reconstr. Surg., 70: $153,1982$.
23- Joa G. and Sampio Goes: Periareolar mammoplasty: Double skin technique with application of polygalactine or mixed mesh. Plast. Reconstr. Surg., 97: 5, 1996.

24- Kejour M. and Abbound M.: Vertical mammoplasty without inframammary scar and with breast liposuction. Perspect. Plast. Surg., 4: 67, 1996.

25- Foustanos A. and Zavrides H.: A double-flap technique: An alternataive mastopexy approach. Plast. Reconstr. Surg., 120: 55-60, 2007.

26- Boehm K.A. and Nahai F.: Mastopexy. In: Nahabedian M.Y., ed. Cosmetic and Reconstructive Breast Surgery. London: Saunders (Elsevier), 109-118, 2008.

27- Ritz M., Silfen R. and Southwick G.: Fascial suspension matoppexy. Plast. Reconstr. Surg., 117: 86-94, 2006.

28- Graf R. and Biggs T.M.: In search of better shape in mastopexy and reduction mammoplasty. Plast. Reconstr. Surg., 110: 309-317, 2002.

29- Adams W.Jr.: Discussion of the article: In search of better shape in mastopexy and reduction mammoplasty by Ruth Graf M.D. and Thomas M. Biggs M.D. Plast. Reconstr. Surg., 110: 321, 2002.

30- Marche D. and de Olarte G.: Reduction mammoplasty and correction of ptoosis with a short inframammary scar. Plast. Reconstr. Surg., 69: 45, 1982.

31- Lejour M.: Vertical mammoplasty and liposuction of the breast. Plast. Reconstr. Surg., 94: 100, 1994.

32- Kejour M.: Vertical mammoplasty: Early complications after 250 personal consecutive cases. Plast. Reconstr. Surg., 104: 764, 1999.

33- Loockwood T.: Reduction mammoplasty and mastopexy with superficial fascial system suspention. Plast. Reconstr. Surg., 103: 1411, 1999.

34- Al-Liethy I. and Emara M.: Superficial fascial system of the breast: A histologic study. Sc. J. Al-Azhar, 26: 2, 2005.

35- Abdelaal M. and Aboelatta Y.A.: Dermo-fascial suuspension; better contouring and long lasting results with reduction mammoplasty. Aesth. Plast. Surg., 39: 78-83 DOI 10.1007/s00266-014-0433-0, 2015.

36- Stevens W.G.1, Stoker D.A., Freeman M.E., Quardt S.M. and Hirsch E.M.: Mastopexy revisited: A review of 150 consecutive cases for complication and revision rates. Aesthet. Surg. J., 27 (2): 150-4. doi: 10.1016/j.asj.2006.12.014, 2007.

37- Migliori F.: Upside-Down augmentation mastopexy. Aesth. Plast. Surg., 35: 593, 2011.

38- Rohrich R.J., Gosman A.A., Brown S.A. and Reisch J.: Mastopexy preferences: A survey of board-certified plastic surgeons. Plast. Reconstr. Surg., 118: 1631-1638, 2006. 